\title{
ATRIBUTOS QUÍMICOS, CARBONO ORGÂNICO E SUBSTÂNCIAS HÚMICAS EM ORGANOSSOLOS HÁPLICOS DE VÁRIAS REGIÕES DO BRASIL ${ }^{(1)}$
}

\author{
Adierson Gilvani Ebeling ${ }^{(2)}$, Lúcia Helena Cunha dos Anjos ${ }^{(3)}$, \\ Daniel Vidal Perez ${ }^{(4)}$, Marcos Gervasio Pereira ${ }^{(3)}$ \& Francisco \\ Wagner de Freitas Gomes ${ }^{(5)}$
}

\begin{abstract}
RESUMO
A dinâmica e os atributos da matéria orgânica do solo (MOS) há muito vêm sendo estudados em solos minerais. Entretanto, em condições tropicais, poucos estudos envolvem os solos orgânicos e a caracterização das substâncias húmicas (SH), ou sua relação com atributos químicos relevantes, para avaliar o potencial agrícola. Os objetivos deste estudo foram: avaliar atributos químicos de Organossolos Háplicos de diferentes regiões do Brasil; quantificar o teor de C orgânico no solo e nas frações da MOS; e avaliar as relações entre esses atributos em cada ambiente de formação. Foram avaliados os atributos químicos e quantificados os teores de C orgânico total e das frações da MOS (ácido fúlvico - CFAF, ácido húmico - C-FAH e humina - C-HUM), bem como as relações C-FAH/CFAF, C-EA/C-HUM, em que C-EA (carbono do extrato alcalino) é obtido pelo somatório de C-FAF e C-FAH. Os Organossolos apresentaram elevada acidez, saturação por bases abaixo de 50 \% e elevada capacidade de troca catiônica

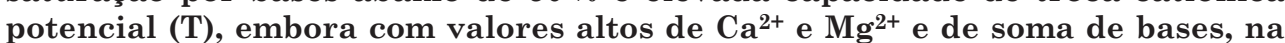
maioria dos perfis. Os teores de $\mathbf{C}$ nas frações húmicas apresentaram correlação significativa com diferentes atributos dos solos, como entre os valores de C-FAH e de C-HUM e os teores de $\mathrm{N}, \mathrm{H}^{+}$e T. O C-HUM e o C-FAH predominaram sobre o CFAF. A relação C-FAH/C-FAF foi menor nos horizontes mais superficiais, dos perfis com maior intensidade de uso ou efeito de queimadas, assim como os teores de
\end{abstract}

(1) Parte da Tese de Doutorado do primeiro autor apresentada ao Curso de Pós-graduação em Agronomia - Ciência do Solo (CPGA-CS) da Universidade Federal Rural do Rio de Janeiro - UFRRJ. Seropédica-RJ. Projeto financiado pelo CNPq. Recebido para publicação em fevereiro de 2010 e aprovado em dezembro de 2010.

(2) Doutorando do CPGA-CS, Universidade Federal Rural do Rio de Janeiro - UFRRJ. BR 465, km 7, CEP 23890-000 Seropédica (RJ). Bolsista do CNPq. E-mail: adiersonge@gmail.com

(3) Professor Associado III, Departamento de Solos, Instituto de Agronomia, UFRRJ. Bolsistas Produtividade do CNPq e FAPERJ. E-mails: lanjos@ufrrj.br; gervasio@ufrrj.br

(4) Pesquisador da Embrapa Solos. Rua Jardim Botânico 1024, CEP 22460-000 Rio de Janeiro (RJ). Bolsista Produtividade do CNPq e FAPERJ. E-mail: daniel@cnps.embrapa.br

(5) Aluno de Graduação do Curso de Agronomia, UFRRJ. Bolsista FAPERJ/IC. E-mail: frwagnerfg@yahoo.com.br 
matéria orgânica, C-HUM e C-FAH. Os atributos químicos e os teores de C nas substâncias húmicas refletiram o grau de transformação da MOS e alterações pelo uso agrícola, indicando a vulnerabilidade dos Organossolos.

Termos de indexação: solos orgânicos, solos hidromórficos, horizonte hístico, frações da matéria orgânica.

\section{SUMMARY: CHEMICAL PROPERTIES, ORGANIC CARBON AND HUMIC SUBSTANCES OF HISTOSOLS IN DIFFERENT REGIONS OF BRAZIL}

The dynamics and properties of soil organic matter (SOM) in mineral soils have been studied for many years. However, under tropical conditions, few studies involve organic soils, the characterization of humic substances (HS), or their relationship with chemical properties related to the agricultural potential of Histosols. The objectives of this study were to characterize chemical properties of Histosols in different Brazilian regions; to quantify soil organic carbon and carbon in the SOM fractions; and to evaluate possible relationships between organic carbon content and soil chemical properties in each environment. The chemical properties were measured and carbon was quantified in the soil samples and the SOM fractions (fulvic acid - C-FAF, humic acid - C-HAF, humin - C-HUM). The ratios $C-H A F / C-F A F, C-E A / C$ $H U M$, where $C$-EA (carbon of the alkaline extract) is equal to the sum of $C-F A F+C-H A F$, were also evaluated. The acidity of the Histosols was high, base saturation below $50 \%$, and the cation exchange capacity (CEC) high, although the Ca and $\mathrm{Mg}$ levels and sum of bases were high in most profiles. The humic fractions were significantly correlated with different soil properties, such as $C$-HAF and also C-HUM with $N, H^{+}$, and CEC. The C-HUM and C-HAF predominated over C-FAF. The C-HAF/C-FAF ratio was reduced in the surface layer of Histosols under intense agricultural use or frequent vegetation burning; the SOM, C-HUM and $C$-HAF contents were also reduced. The chemical properties and $C$ content in the humic substances reflected the transformation degree of SOM and the changes caused by agricultural use, indicating the vulnerability of Histosols.

Index terms: Organic soils, hydromorphic soils, histic epipedon, soil organic matter fractions.

\section{INTRODUÇÃO}

Os solos orgânicos são formados a partir de materiais depositados em condições que favorecem o acúmulo de material vegetal por excessiva umidade, baixo $\mathrm{pH}$ ou disponibilidade de nutrientes, escassez de $\mathrm{O}_{2}$ e baixas temperaturas, conduzindo à redução da intensidade dos processos de mineralização e de humificação. Gerações consecutivas de vegetais transformam-se em turfa, sendo os materiais empilhados em camadas, com variações nas propriedades físicas e químicas em função da composição vegetal, do grau de decomposição e da quantidade de matéria orgânica (MO) (Garcia, 1996).

A interferência antrópica em ecossistemas altamente frágeis, como os Organossolos, produz mudanças na dinâmica da matéria orgânica (Stevenson, 1994), com redução no teor e modificações na qualidade ao longo do tempo. As práticas de uso e manejo agrícola interferem no equilíbrio natural dos processos de pedogênese nos Organossolos, acelerando as perdas de $\mathrm{MO}, \mathrm{C}, \mathrm{N}$ e outros nutrientes, além da subsidência (Pereira et al., 2005), alterando assim atributos químicos e as relações entre as substâncias húmicas da MOS.

Com a drenagem artificial dos Organossolos para uso agrícola, ocorre rápida oxidação da MO do solo, com liberação de $\mathrm{CO}_{2}$, diminuição de volume e gradativo aumento dos valores da densidade do solo e das partículas, modificando suas características originais (Pereira et al., 2005). Os Organossolos de ambiente de várzea apresentam, em geral, características como elevada acidez e baixa saturação por bases (Ebeling et al., 2008; Valladares et al., 2008), bem como baixos teores de macro e micronutrientes. Esses atributos podem levar ao baixo potencial de uso agrícola, quando drenados; por outro lado, esses solos têm alta vulnerabilidade e grande relevância para preservação de mananciais hídricos e na conservação de ecossistemas.

Tendo em vista que os Organossolos foram pouco estudados em ambientes tropicais, e visando contribuir para o seu uso sustentável, os objetivos deste estudo foram: avaliar atributos químicos de Organossolos 
Háplicos de diferentes regiões do Brasil; quantificar o teor de C orgânico do solo e das frações da MOS; e avaliar as relações entre esses atributos nos diferentes ambientes de formação, cobertura vegetal e intensidade de uso agrícola.

\section{MATERIAL E MÉTODOS}

\section{Localização e caracterização morfológica dos perfis de Organossolos}

Foram coletados em trincheiras sete perfis de Organossolos, perfazendo um total de 28 horizontes orgânicos, em diferentes regiões do Estado do Rio de Janeiro (coordenadas de $22^{\circ} 35^{\prime} \mathrm{S}$ e $42^{\circ} 15^{\prime} \mathrm{W}-$ perfil RJ01; $22^{\circ} 31^{\prime} \mathrm{S}$ e $42^{\circ} 20^{\prime} \mathrm{W}$ - perfil RJ02; $23^{\circ} 17^{\prime} \mathrm{S} 41^{\circ} 52^{\prime} \mathrm{W}$ - perfil RJ03; $22^{\circ} 17^{\prime} \mathrm{S}$ $41^{\circ} 52^{\prime} \mathrm{W}$ - perfil RJ04; $22^{\circ} 20^{\prime} \mathrm{S}$ e $41^{\circ} 57^{\prime} \mathrm{W}-$ perfil RJ08), no Maranhão (coordenadas de $3^{\circ} 32^{\prime} \mathrm{S}$ e $45^{\circ} 12^{\prime} \mathrm{W}$ - perfil MA05) e no Paraná (coordenadas de $25^{\circ} 14^{\prime} \mathrm{S}$ e $50^{\circ} 01^{\prime} \mathrm{W}$ - perfil PR06). A identificação dos perfis e paisagem é resumida no quadro 1, e as características morfológicas são apresentadas no quadro 2.

Os solos foram coletados em áreas com distintas condições de uso e cobertura vegetal, representativas de ambientes de várzea em clima tropical (RJ e MA) e clima temperado (PR). No Estado do Maranhão ocorrem diferenças na sazonalidade e distribuição do período chuvoso; a condição é típica de clima equatorial, e a precipitação pluvial concentra-se em cinco a seis meses (de dezembro/janeiro a maio/junho). No Rio de Janeiro, as chuvas são mais intensas no verão e ocorrem em alguns meses no outono e primavera - portanto, com melhor distribuição.

A coleta dos materiais foi feita segundo Santos et al. (2005). Os solos foram caracterizados quanto às suas propriedades químicas segundo Embrapa (1997, 2006) e classificados no Sistema Brasileiro de Classificação de Solos - SiBCS (Embrapa, 2006).

\section{Análises químicas}

Foram determinados o $\mathrm{pH}$ em água e em $\mathrm{KCl}$ $1 \mathrm{~mol} \mathrm{~L}-1$, além dos teores de $\mathrm{Ca}^{2+}, \mathrm{Mg}^{2+}, \mathrm{K}^{+}, \mathrm{Na}^{+}, \mathrm{Al}^{3+}$, $\mathrm{H}+\mathrm{Al}, \mathrm{H}^{+}$e P. Foram calculadas a soma de bases (SB), a capacidade de troca catiônica potencial do solo (T), a saturação por bases (V) e a saturação por sódio e por alumínio (Embrapa, 1997). O C foi determinado pelo método de combustão a seco, no CHN (C-CHN) analisador elementar modelo Perkin Elmer 2400 CHNS da Embrapa Solos, quantificando-se o $\mathrm{CO}_{2}$ desprendido a partir da combustão de amostras sólidas, usando $\mathrm{O}_{2}$ atmosférico, em temperaturas superiores a $950{ }^{\circ} \mathrm{C}$. Um catalisador converte o $\mathrm{CO}$ em $\mathrm{CO}_{2} \mathrm{e}$ sua quantificação é feita por meio de um detector infravermelho (Nelson \& Sommers, 1982). O teor de matéria orgânica foi determinada por combustão em forno mufla, conforme descrito por Embrapa (1997), com modificações segundo Embrapa (2006).

Quadro 1. Identificação, localização, uso atual e drenagem, classificação e altura do lençol freático nos perfis de Organossolos nos Estados do Rio de Janeiro, Maranhão e Paraná

\begin{tabular}{|c|c|c|c|c|}
\hline Estado $^{(1)} /$ Perfil & Município & Vegetação/drenagem/ambiente & Classificação dos solos (SiBCS) & Altura do lençol \\
\hline RJ02 & Silva Jardim & $\begin{array}{l}\text { Floresta higrófila de várzea, sem } \\
\text { uso agrícola. Muito mal drenado(2) }\end{array}$ & $\begin{array}{l}\text { Organossolo } \\
\text { Háplico sáprico típico }\end{array}$ & $\begin{array}{l}\mathrm{cm} \\
43\end{array}$ \\
\hline RJ08 & Macaé & $\begin{array}{l}\text { Campo higrófilo de várzea, área } \\
\text { sem uso agrícola. Muito mal drenado(2) }\end{array}$ & $\begin{array}{l}\text { Organossolo } \\
\text { Háplico hêmico típico }\end{array}$ & 60 \\
\hline RJ01 & Silva Jardim & $\begin{array}{l}\text { Floresta higrófila de várzea e campo } \\
\text { higrófilo, sem uso agrícola e com } \\
\text { queimadas regulares - Muito } \\
\text { mal drenado }(2)\end{array}$ & $\begin{array}{l}\text { Organossolo } \\
\text { Háplico hêmico } \\
\text { térrico }\end{array}$ & 116 \\
\hline RJ03 & Macaé & $\begin{array}{l}\text { Floresta higrófila de várzea e } \\
\text { campo higrófilo - Mal drenado }(2)\end{array}$ & $\begin{array}{l}\text { Organossolo } \\
\text { Háplico hêmico típico }\end{array}$ & 43 \\
\hline RJ04 & Macaé & 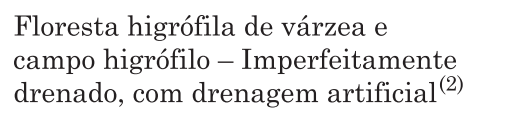 & $\begin{array}{l}\text { Organossolo } \\
\text { Háplico sáprico } \\
\text { típico }\end{array}$ & 120 \\
\hline MA05 & Mo nção & $\begin{array}{l}\text { Campo de várzea higrófilo - } \\
\text { Muito mal drenado( })\end{array}$ & $\begin{array}{l}\text { Organossolo Háplico } \\
\text { sáprico típico }\end{array}$ & 60 \\
\hline PR06 & Ponta Grossa & $\begin{array}{l}\text { Campo subtropical - Mal } \\
\text { drenado(3) }\end{array}$ & $\begin{array}{l}\text { Organossolo Háplico } \\
\text { hêmico típico }\end{array}$ & 55 \\
\hline
\end{tabular}

\footnotetext{
(1) Estados brasileiros: RJ - Rio de Janeiro, MA - Maranhão, PR - Paraná. Para comparação, os perfis no RJ foram ordenados em função da menor intensidade de uso, e os demais, por Estado. ${ }^{(2)}$ Solos formados em ambientes de várzeas de planícies litorâneas; (3) Solo formado em várzeas de planalto.
} 
Quadro 2. Algumas características morfológicas dos perfis de Organossolos

\begin{tabular}{|c|c|c|c|c|}
\hline Perfil-Horizonte & Espessura & Cor Munsel (úmida) & Consistência & Estrutura \\
\hline & $\mathrm{cm}$ & & & \\
\hline RJ02 - Hdo & $0-19$ & 10YR $2 / 2$ & solta/firme & maciça com poucas fibras \\
\hline RJ02 -Ho1 & $19-40$ & 10YR 3/1 & $\mathrm{macia} /$ dura & maciça com muitas fibras \\
\hline RJ02 - Ho2 & $40-67^{+}$ & 10YR $3 / 2$ & muito dura, muito friável & aspecto maciço muito fibrosa \\
\hline RJ08 -Hdo & $0-19$ & 10YR 2/1 & dura/firme & mod. peq.gran. \\
\hline RJ08 -Ho1 & $19-40$ & $10 \mathrm{YR} 2 / 2$ & dura/firme & maciça/ muitas fibras grandes \\
\hline RJ08 -Ho2 & $40-67^{+}$ & $10 \mathrm{YR} 2 / 2$ & dura/firme & maciça/mui tas fibras grandes \\
\hline RJ01 -Hd1 & $0-12$ & 10YR 2/1 & muito friável & granular \\
\hline RJ01 -Hd2 & $12-24$ & 10YR 3/3/10YR 4/4 & muito friável, lig. dura & granular \\
\hline RJ01 - Cg1 & $24-46$ & $5 Y R 4 / 1$ & firme/lig. dura & maciça \\
\hline RJ01 - Cg2 & $46-57$ & 7,5 YR 7/2 & firme/lig. dura & maciça \\
\hline RJ01 - 2Hbd1 & $57-76$ & 10YR 2/2/2,5YR 4/4 & macia/m. friável & bl. subang. \\
\hline RJ01 - $2 \mathrm{Hbd} 2$ & $76-116$ & $10 Y R 2 / 1$ & macia/m. friável & maciça \\
\hline RJ01 - 2Hbd3 & $116-206^{+}$ & 10YR $3 / 2$ & macia/ firme & maciça \\
\hline RJ03 -Hdp1 & $0-6$ & $10 \mathrm{YR} 2 / 2$ & dura/firme & bl. subang. \\
\hline RJ03 -Hdp2 & $6-17$ & 10YR 3/1 & dura/firme & bl. subang. \\
\hline RJ03 - Cg & $17-20$ & 10YR 5/2 & dura/firme & maciça \\
\hline RJ03 - $2 \mathrm{Hbd}$ & $20-32$ & 10YR 2/1 & dura/firme & maciça \\
\hline RJ03 - $2 \mathrm{Cbg}$ & $32-38$ & $10 Y R 5 / 2$ & dura/firme & maciça \\
\hline RJ03 - 3Hbd & $38-56^{+}$ & 10YR 2/1 & dura/firme & maciça \\
\hline RJ04 - Hdp1 & $0-10$ & 10YR 2/1 & dura/friável & mod.peq.granular \\
\hline RJ04 -Hdp2 & $10-20$ & 10YR 2/1 & muito dura/firme & maciça a fraca pequena granular \\
\hline RJ04 - Cg & $20-28$ & 10YR 6/1 & muito dura/firme & maciça \\
\hline RJ04 - $2 \mathrm{Hbd}$ & $28-33$ & 10YR N 2 & solta friável & granular \\
\hline RJ04 - 2Cbg & $33-38$ & 10YR 6/2 & muito dura/firme & maciça \\
\hline RJ04 - 3Hbd 1 & $38-53$ & 10YR 2/1 & solta/friável & maciça com fibra \\
\hline RJ04 - 3Hbd 2 & $53-71^{+}$ & 10YR 5/2 & solta/friável & maciça com fibra \\
\hline MA05 -Hdo1 & $0-17$ & 10YR N 2 & muito friável/dura & maciça/muito peq. granular \\
\hline MA05 - Hdo2 & $17-41$ & 10YR N 2 & m. dura/m. friável & maciça \\
\hline MA05 - Cg & $41-46$ & 10YR 7/3 & dura/firme & maciça \\
\hline MA05 - $2 \mathrm{Hbd} 1$ & $46-61$ & 10YR N 2 & m. dura/m. friável & maciça \\
\hline MA05 - $2 \mathrm{Hbd} 2$ & $61-74^{+}$ & 10YR N 2 & m. dura/m. friável & maciça \\
\hline PR06 -Hdo 1 & $0-19$ & 10YR N 2 & macia/m. friável & peq. granular \\
\hline PR06 - Hdo2 & $19-42$ & 10YR N 2 & m. fria/lig. dura & maciça \\
\hline PR06 - Hdo3 & $42-55$ & 10YR 2/1 & friável/lig. dura & maciça \\
\hline PR06 - Hd o 4 & $55-75^{+}$ & $10 \mathrm{YR} 2 / 2$ & dura/friável & maciça \\
\hline
\end{tabular}

(1) Estados brasileiros: RJ - Rio de Janeiro, MA - Maranhão, PR - Paraná. Para facilidade de comparação, os perfis RJ foram ordenados em função da menor intensidade de uso, e os demais, por Estado.

\section{Fracionamento químico das substâncias} húmicas

O fracionamento químico das substâncias húmicas foi feito em triplicata, segundo a técnica de solubilidade diferencial, e os conceitos de frações húmicas, estabelecidos pela Sociedade Internacional de Substâncias Húmicas, adaptados por Benites et al. (2003). Após a extração, o teor de C nos extratos das frações húmicas (ácido húmico, ácido fúlvico e humina) foi quantificado segundo Nelson \& Sommers (1982). Foram calculadas as relações entre os teores de $\mathrm{C}$ das frações ácido húmico e ácido fúlvico (C-FAH/ C-FAF) e a relação entre as frações solúveis do extrato alcalino e o teor de C na fração humina (C-EA/CHUM), em que C-EA (C do extrato alcalino) é $\mathrm{C}-\mathrm{EA}=\mathrm{C}$ $\mathrm{FAF}+\mathrm{C}-\mathrm{FAH}$.

\section{Análises estatísticas}

Para comparação dos resultados, cada perfil e ambiente ou uso agrícola foi considerado como único e foram analisadas as diferenças entre os atributos químicos e os da MOS. As inferências sobre os resultados foram efetuadas com base em técnicas de estatística descritiva, análises de regressão linear simples e correlação de Pearson. Todos os resultados foram testados para os níveis de probabilidade de 0,1; 0,05 e 0,01.

\section{RESULTADOS E DISCUSSÃO}

\section{Ambiente, histórico e classificação dos Organossolos}

Os perfis RJ01 a RJ04 e o RJ08 estão localizados na região Sudeste, em ambiente tropical úmido, feição de mata atlântica em várzeas litorâneas. $O$ perfil MA05, na região pré-amazônica maranhense, está em zona equatorial, também em feição de várzea, porém em ambiente lagunar. O perfil PR06, na região sul, está em ambiente de várzea, mas em clima subtropical de altitude e com campo subtropical (Quadro 1). 
O perfil RJ01 localiza-se na Reserva Biológica Poço das Antas (REBIO - Casemiro de Abreu/Silva Jardim), em área onde, periodicamente, ocorrem queimadas devido ao próprio acúmulo de biomassa vegetal e às características da turfa. Após a queimada, que pode durar vários dias, o solo é novamente recoberto pela vegetação. Este perfil apresenta horizontes orgânicos intercalados com horizontes minerais (Quadro 2). O perfil RJ02 situa-se em Silva Jardim, às margens da BR 101, em área que até pouco tempo antes da amostragem era recoberta com vegetação de floresta tropical de várzea e alagada em grande parte do ano. Este perfil apresenta material em estádio inicial de decomposição sobre o solo, na forma de folhas, galhos e troncos de árvores e arbustos. Nota-se ainda material (tecido vegetal ainda identificável) pouco alterado e uniforme, principalmente nos horizontes Ho1 e Ho2, com muitas fibras. O lençol freático, o mais próximo à superfície do solo, estava a $43 \mathrm{~cm}$, coincidente com o Ho2 (Quadro 1).

No município de Macaé (RJ) localizam-se os perfis RJ03 e RJ04, em propriedades rurais às margens da BR 101, ambos originalmente sob vegetação de floresta higrófila de várzea e campo higrófilo, muito mal drenado e drenado, respectivamente. No final da década de 1970, essas áreas foram drenadas para agricultura, com lavouras de arroz inundado em rotação com feijão e milho. Nos últimos 10 anos, a área do perfil RJ03 tem sido utilizada para pastagem consorciada em sistema rotacionado, e a do perfil RJ04 tem intenso uso, com lavouras anuais rotacionadas de milho e feijão, com revolvimento por mecanização constante e uso intenso de adubos e defensivos. Ainda, na área do perfil RJ03 os drenos têm menor profundidade; logo, no período chuvoso o lençol está próximo à superfície do solo. No perfil RJ04, a profundidade dos drenos é de 1,5 a $2 \mathrm{~m}$. Nesses dois perfis, ocorrem horizontes $\mathrm{Cg}$ intercalados com horizontes orgânicos. Destaca-se nesses perfis a consistência dura/firme e muito dura/firme quando seco e úmido e a estrutura granular e blocos subangulares nos dois primeiros horizontes (Quadro 2).

O perfil MA05 foi coletado na área inundável do lago Anananzal, em assentamento com o mesmo nome, sendo cultivado em lavouras de subsistência, como milho e arroz, em sistema de manejo primitivo, por cerca de seis meses no ano no período seco, que é bem definido no Estado do Maranhão. Na época das cheias, a área é inundada e a lâmina de água recobre toda a área de cultivo; assim, novos materiais orgânicos e minerais são adicionados, formando um Organossolo onde os processos pedogenéticos se alternam anualmente com os de sedimentação. Este perfil também apresenta horizontes orgânicos intercalados com horizontes minerais; destaca-se ainda a cor negra dos horizontes e a consistência variando de dura a muito dura (Quadro 2). O lençol freático estava a cerca de $60 \mathrm{~cm}$ da superfície na época de coleta.

O perfil PR06 está em ambiente de várzea, porém com altitude mais elevada, em feição de planalto em
Ponta Grossa (PR), e também não foi drenado artificialmente.

O perfil RJ08, sob vegetação de campo higrófilo de várzea, localiza-se no mesmo ambiente dos perfis RJ03 e RJ04. Essa área, pela sua situação na paisagem, abaciada e entre morros de relevo ondulado e suave ondulado, permanece com lençol freático elevado quase todo o ano e não foi utilizada para lavoura ou pastagem. Este perfil foi tomado como de referência para comparar variações na natureza da matéria orgânica, em função do uso agrícola, e efeitos da drenagem sobre a subsidência dos Organossolos. Destaca-se neste perfil a presença de muitas fibras grandes, identificáveis a olho nu, porém muito frágeis, desfazendo-se com pouco manuseio, além de material lenhoso em estádio intermediário de decomposição. A consistência do material, quando seco, mostrou-se dura (Quadro 2).

Todos os perfis foram classificados como Organossolos Háplicos, de acordo com o SiBCS (Embrapa, 2006), o que foi um pré-requisito para o estudo, de forma que permitisse homogeneidade dos solos no nível taxonômico de subordem. Os perfis RJ01, RJ03, RJ8 e o PR06 foram classificados como Organossolos Háplicos hêmicos típicos, e os demais, como Organossolos Háplicos sápricos típicos. O perfil RJ01 foi classificado como Organossolo Háplico hêmico térrico, por apresentar camadas constituídas por material mineral $(\mathrm{Cg})$ com espessura cumulativa de $33 \mathrm{~cm}$, dentro de $100 \mathrm{~cm}$ da superfície.

\section{Carbono orgânico, nitrogênio e relação C/N em Organossolos}

O teor de C determinado pelo CHN variou de 41,2 a $499,1 \mathrm{~g} \mathrm{~kg}^{-1}$, com valor médio de $193,1 \mathrm{~g} \mathrm{~kg}^{-1} \mathrm{e}$ coeficiente de variação de 70,6 \% (Quadro 3). Fontana et al. (2008b) encontraram, para Organossolos, variações de $\mathrm{C}$ de 114,3 a 568,8 $\mathrm{g} \mathrm{kg}^{-1}$, com média de $351,3 \mathrm{~g} \mathrm{~kg}^{-1}$. Ebeling et al. (2008) quantificaram valores de $\mathrm{C}$ variando de 39,0 a $528,1 \mathrm{~g} \mathrm{~kg}^{-1}$, com valor médio de $237,5 \mathrm{~g} \mathrm{~kg}^{-1}$ e coeficiente de variação de $61 \%$. Essa grande variação no teor de C está relacionada às condições ambientais dos locais de amostragem e à própria heterogeneidade das camadas de depósitos orgânicos, refletindo, portanto, variações de cobertura vegetal, clima, água e umidade, ao longo do tempo. Ressalta-se ainda que, mesmo dentro da mesma subordem - Organossolos Háplicos, a grande variação em sua principal característica diagnóstica é relevante para avaliar potencialidade agrícola e vulnerabilidade à degradação.

Os teores de $\mathrm{N}$ variaram entre 2,8 e $21,3 \mathrm{~g} \mathrm{~kg}^{-1}$, com valor médio de $10,9 \mathrm{~g} \mathrm{~kg}^{-1}$, apresentando muito alta correlação com o C-CHN ( $r=0,938, p \geq 0,000)$, ou seja, quanto maior o teor de C, maiores os teores de N. Entretanto, quanto à disponibilidade de $\mathrm{N}$ para as culturas, indicada pela relação $\mathrm{C} / \mathrm{N}$ (que variou de $8,9$ a 27,7$)$, os valores mais elevados indicam que em alguns horizontes (nos perfis RJ02 e RJ08) o N 
encontrava-se em formas não disponíveis, como nos tecidos vegetais lignificados, ou em material muito pouco decomposto, como as fibras.

\section{Frações húmicas e relações entre atributos nos Organossolos}

A fração humina (C-HUM) predominou em todos os perfis, com os maiores teores médios observados nos perfis RJ08 e RJ02 com valores de 285,6 e 248, $4 \mathrm{~g} \mathrm{~kg}^{-1}$, respectivamente (Quadro 3). O predomínio da humina em ambientes hidromórficos é atribuído à humificação direta dos tecidos lignificados modificados por processos de demetilação, além da presença de humina hereditária (Duchaufour \& Souchier, 1977). Para Breemen \& Buurman (2002), a humina representa a fração mais heterogênea da matéria orgânica do solo, formada por compostos organominerais, carvão, componentes apolares e restos vegetais não decompostos.
Os menores teores de C-HUM foram observados nos horizontes $\mathrm{Hd} 1$, $\mathrm{Hd} 2$ e $2 \mathrm{Hbd} 1$ do perfil RJ01, com valores de 31,5 , 19,3 e 42,0 $\mathrm{g} \mathrm{kg}^{-1}$, respectivamente (Quadro 3). Esses baixos teores de C-HUM foram devidos a frequentes queimadas, nos últimos anos, na área onde o perfil foi coletado. Maiores teores de CHUM foram observados nos horizontes $2 \mathrm{Hbd} 2$ e $2 \mathrm{Hbd} 3$ do perfil RJ01, os quais estavam protegidos pelo horizonte $\mathrm{Cg}$ acima destes, sendo preservados dos efeitos da ação antrópica.

Os perfis RJ03, RJ04 e MA05 apresentaram os menores teores médios de C-HUM: 91,7, 81,4 e $57,7 \mathrm{~g} \mathrm{~kg}^{-1}$, respectivamente (Quadro 3). A drenagem e o intenso revolvimento do solo podem acelerar as perdas de C. Esse efeito pode levar à mineralização até mesmo das frações mais estáveis, como o C-FAH e C-HUM, alterando assim a resiliência dos Organossolos. O mesmo padrão de aumento foi

Quadro 3. Teores de matéria orgânica (MO), carbono total (C-CHN), C nas frações da matéria orgânica e suas relações, em horizontes orgânicos de Organossolos nos Estados do Rio de Janeiro, Maranhão e Paraná

\begin{tabular}{|c|c|c|c|c|c|c|c|c|}
\hline Perfil & Horizonte & MO & C-CHN & C-FAH & C-FAF & C-HUM & C-FAH/C-FAF & EA/ HUM \\
\hline & & \multicolumn{5}{|c|}{$\mathrm{g} \mathrm{kg}^{-1}$} & & \\
\hline RJ02 & Hdo & 745,83 & 368,0 & 88,1 & 10,8 & 253,8 & 11,6 & 0,4 \\
\hline RJ02 & Ho1 & 837,16 & 496,1 & 87,1 & 11,6 & 268,3 & 8,7 & 0,4 \\
\hline RJ02 & Ho2 & 694,26 & 362,8 & 67,4 & 20,8 & 223,2 & 3,4 & 0,4 \\
\hline RJ08 & Hdo & 556,92 & 276,5 & 56,4 & 22,4 & 194,5 & 2,6 & 0,4 \\
\hline RJ08 & Ho1 & 773,99 & 446,4 & 89,7 & 12,8 & 344,0 & 7,0 & 0,3 \\
\hline RJ08 & Ho2 & 713,81 & 499,1 & 79,1 & 8,2 & 318,2 & 9,8 & 0,3 \\
\hline RJ01 & Hd1 & 148,80 & 66,2 & 15,8 & 16,2 & 31,5 & 1,0 & 1,1 \\
\hline RJ01 & $\mathrm{Hd} 2$ & 116,66 & 41,2 & 6,2 & 13,0 & 19,3 & 0,5 & 1,1 \\
\hline RJ01 & $2 \mathrm{Hbd} 1$ & 160,81 & 82,4 & 24,8 & 11,5 & 42,0 & 2,3 & 0,9 \\
\hline RJ01 & $2 \mathrm{Hbd} 2$ & 467,39 & 249,9 & 96,8 & 13,1 & 125,6 & 7,4 & 0,9 \\
\hline RJ01 & $2 \mathrm{Hbd} 3$ & 443,89 & 233,0 & 80,2 & 15,7 & 124,4 & 5,1 & 0,8 \\
\hline RJ03 & Hdp1 & 222,68 & 116,4 & 35,8 & 16,2 & 60,1 & 2,3 & 0,9 \\
\hline RJ03 & Hdp2 & 254,41 & 125,9 & 43,8 & 14,1 & 54,1 & 3,2 & 1,1 \\
\hline RJ03 & $2 \mathrm{Hbd}$ & 335,17 & 178,2 & 50,5 & 14,3 & 78,8 & 3,7 & 0,8 \\
\hline RJ03 & $3 \mathrm{Hbd}$ & 530,26 & 306,0 & 93,6 & 10,3 & 173,8 & 9,9 & 0,6 \\
\hline RJ04 & Hdp1 & 278,02 & 129,7 & 38,5 & 12,6 & 57,8 & 3,1 & 0,9 \\
\hline RJ04 & Hdp2 & 392,33 & 136,1 & 58,1 & 12,2 & 62,6 & 4,8 & 1,1 \\
\hline RJ04 & $2 \mathrm{Hbd}$ & 362,07 & 161,2 & 56,1 & 8,0 & 80,9 & 7,6 & 0,8 \\
\hline RJ04 & $3 \mathrm{Hbd} 1$ & 348,10 & 171,5 & 56,6 & 9,6 & 80,5 & 6,4 & 0,8 \\
\hline RJ04 & $3 \mathrm{Hbd} 2$ & 415,75 & 226,3 & 64,7 & 8,7 & 125,2 & 8,6 & 0,6 \\
\hline MA 05 & Hdo1 & 355,48 & 154,1 & 34,2 & 12,7 & 96,5 & 3,0 & 0,5 \\
\hline MA05 & Hdo2 & 208,25 & 110,4 & 23,5 & 9,0 & 64,5 & 2,9 & 0,5 \\
\hline MA05 & $2 \mathrm{Hbd} 1$ & 131,00 & 51,4 & 11,9 & 3,1 & 30,0 & 5,0 & 0,5 \\
\hline MA05 & $2 \mathrm{Hbd} 2$ & 143,11 & 57,1 & 14,3 & 2,1 & 39,6 & 6,9 & 0,4 \\
\hline PR06 & Hdo 1 & 405,06 & 139,8 & 34,5 & 12,5 & 122,6 & 2,8 & 0,4 \\
\hline PR06 & Hdo2 & 291,51 & 119,4 & 39,0 & 8,9 & 90,4 & 4,4 & 0,5 \\
\hline PR06 & Hdo3 & 154,17 & 57,3 & 24,4 & 4,3 & 23,5 & 5,7 & 1,2 \\
\hline PR06 & Hdo 4 & 126,67 & 43,1 & 16,9 & 3,2 & 8,0 & 5,3 & 2,5 \\
\hline Máximo & & 837,2 & 499,1 & 96,8 & 22,4 & 344,0 & 11,6 & 2,5 \\
\hline Mínimo & & 116,7 & 41,2 & 6,2 & 2,1 & 8,0 & 0,5 & 0,3 \\
\hline Média & & 379,1 & 193,1 & 48,9 & 11,4 & 114,1 & 5,2 & 0,8 \\
\hline $\mathrm{Dp}$ & & 217,1 & 136,3 & 27,8 & 4,8 & 92,8 & 2,9 & 0,4 \\
\hline CV (\%) & & 57,3 & 70,6 & 56,0 & 42,2 & 81,3 & 55,2 & 58,7 \\
\hline
\end{tabular}

MO: matéria orgânica determinada em forno mufla; C-CHN: carbono total determinado pelo analisador elementar CHN; CFAH: carbono da fração ácido húmico; C-FAF: carbono da fração ácido fúlvico; C-HUM: carbono da fração humina; C-FAH/CFAF: razão entre o $\mathrm{C}$ da fração ácido húmico e o da fração ácido fúlvico; EA:HUM: razão entre o extrato alcalino (soma entre o $\mathrm{C}$ do ácido húmico e o $\mathrm{C}$ do ácido fúlvico) pelo $\mathrm{C}$ da fração humina. 
observado nos horizontes $2 \mathrm{Hbd}$ do perfil RJ03 e $3 \mathrm{Hbd} 2$ do perfil RJ04, com teores de C-HUM de 173,8 e $125,2 \mathrm{~g} \mathrm{~kg}^{-1}$, respectivamente, ambos com horizonte mineral (Cg) sobrejacente. Os perfis RJ02 e RJ08 foram tomados como perfis de referência para Organossolos em estado próximo ao natural, no ambiente de várzea e sem uso agrícola.

Trabalhando com solos de turfa da região nordeste da Alemanha, Kalbitz \& Geyer (2002) encontraram redução para 10 e $50 \%$ do C.org total original de solos cultivados por 50 e 200 anos, em comparação com solos de turfa praticamente inalterados.

Considerando-se os valores médios das três repetições do fracionamento da MOS, o C-HUM apresentou valor máximo de $334,0 \mathrm{~g} \mathrm{~kg}^{-1}$ e mínimo de $8,0 \mathrm{~g} \mathrm{~kg}^{-1}$, com média de $114,1 \mathrm{~g} \mathrm{~kg}^{-1}$ e desviopadrão elevado de $92,8 \mathrm{~g} \mathrm{~kg}^{-1}$, com alto coeficiente de variação (81,3\%), representando 59,08 \% do $\mathrm{C}$ total determinado pelo CHN (C-CHN). Esses resultados são semelhantes ao observado por Fontana et al. (2008b), estudando Organossolos em diferentes regiões do Brasil, os quais encontraram valores muito próximos de coeficientes de variação para C-HUM, e para valores mínimos e máximos. Em ambos os estudos, os resultados demonstram que também nos Organossolos o C-HUM é predominante, sendo o principal responsável pelo sequestro de $\mathrm{C}$ em solos.

O C-FAF correspondeu a $5,88 \%$ do $\mathrm{C}$ total, mostrando que a maior parte da MOS encontra-se mais transformada, com predomínio das frações mais recalcitrantes (FAH e HUM), em função da maior presença de grupamentos aromáticos e de anéis benzênicos, do maior grau de polimerização e da menor suscetibilidade ao ataque microbiano (Stevenson, 1994). O C-FAF apresentou o menor valor médio $\left(11,4 \mathrm{~g} \mathrm{~kg}^{-1}\right)$ e a menor variabilidade, com coeficiente de 42,2\%. Ele apresentou valor mínimo de $2,1 \mathrm{~g} \mathrm{~kg}^{-1}$, no horizonte $2 \mathrm{Hbd} 2$ do perfil MA05, e máximo de 22,4 $\mathrm{g} \mathrm{kg}^{-1}$, no Hdo do perfil RJ08.

O C-FAH apresentou valor médio de $48,9 \mathrm{~g} \mathrm{~kg}^{-1} \mathrm{e}$ coeficiente de variação de $56 \%$. Seus valores mínimo e máximo foram de 6,2 e 96,8 $\mathrm{g} \mathrm{kg}^{-1}$, nos horizontes $\mathrm{Hd} 2 \mathrm{e} 2 \mathrm{Hbd} 2$ do perfil RJ01, respectivamente. O CFAH correspondeu a $25,7 \%$ do $\mathrm{C}$ total.

A razão C-FAH/C-FAF foi inicialmente usada por Kononova (1982) como indicador da qualidade das substâncias húmicas, para expressar o grau de evolução do processo de humificação. Em solos tropicais, normalmente, essa relação é menor que 1 , devido à menor intensidade dos processos de humificação, como a condensação e síntese, intensa mineralização dos resíduos, restrições edáficas e baixo teor de bases, restringindo a atividade biológica nos solos intensamente intemperizados (Cerri \& Volkoff, 1988).

Nos Organossolos a relação C-FAH/C-FAF variou de 0,5 a 11,6 , com valor médio de 5,2. Apenas um horizonte orgânico apresentou valor menor que 1,0, o que indica o predomínio da fração ácido húmico nas amostras dos Organossolos, destacando-se que, quanto mais alto o grau de hidromorfismo, maior será essa relação e maior o grau de polimerização e condensação (Valladares et al., 2007). Altos valores dessa relação foram também observados por Fontana et al. (2008a). Estes autores estudaram Organossolos em ambiente hidromórfico e de altitude, bem drenados, e horizontes superficiais com alto teor de matéria orgânica de outras classes de solos.

A evolução do húmus pode ser modificada pelo hidromorfismo, como apontado por Silva et al. (2009), que encontraram para um Organossolo drenado há mais de dois séculos valores da relação C-FAH/C-FAF de 0,29 a 0,54 . Nos horizontes mais profundos, em ambientes muito mal drenados; a via de herança (evolução direta dos compostos insolúveis lignificados da matéria orgânica pouco transformada) é o processo de humificação predominante. Outras vias de humificação, como a de neossíntese microbiana, que consiste na humificação das moléculas simples por meio da síntese microbiana, e a de insolubilização ou humificação dos compostos fenólicos solúveis, necessitam de elevada pressão de $\mathrm{O}_{2}$ para manter a atividade da microbiota do solo (Dablin, 1981).

Esse padrão pode ser observado nos horizontes Hd1, Hd2 e 2Hbd1 do perfil RJ01 que foram alterados por queimadas, modificando o teor de $\mathrm{C}$ nos horizontes e reduzindo a relação C-FAH/C-FAF, bem como nos horizontes Hdp1, Hdp2 e 2Hbd do perfil RJ03 e Hdp1 e Hdp2 do perfil RJ04, usados com agricultura e pastagem e com revolvimento do solo. Os horizontes abaixo da camada arável não apresentam redução da relação C-FAH/C-FAF, e sim o seu aumento em profundidade.

A relação EA/HUM apresentou grande variação, com valores entre 0,3 e 2,5 (média de 0,8 ), porém $95 \%$ das amostras apresentaram valores inferiores a 2 . Segundo Benites et al. (1998), essa relação fornece informações sobre processos pedogenéticos. Estudando horizontes espódicos, Fontana et al. (2008b) observaram picos da relação EA/HUM nesses horizontes; ainda, encontraram valores de EA/HUM menores que 2 para a maioria dos horizontes orgânicos. Nos Organossolos não foi observado padrão de acréscimo ou decréscimo da relação com a profundidade, ao contrário do que ocorre em Espodossolos, por exemplo. Esse fato indica que vários são os fatores que influenciaram a proporção de compostos alcalinossolúveis ou insolúveis, incluindo vegetação e, principalmente, ambiente de formação e clima, nos vários eventos de deposição de material orgânico ao longo do tempo.

Relação entre o teor de carbono das substâncias húmicas e atributos químicos

$\mathrm{O}$ valor $\mathrm{T}$ apresentou correlação positiva $\mathrm{e}$ significativa com C-FAH, C-HUM, C-CHN e N (Quadro 4), o que indica o importante papel dessas 
Quadro 4. Coeficientes de correlação entre alguns atributos químicos de Organossolos

\begin{tabular}{lccccccccc}
\hline & C-CHN & N & SB & H $^{+}$ & C-FAH & C-FAF & C-HUM & MO & P \\
\hline T & $\mathbf{0 , 8 0 1}$ & $\mathbf{0 , 7 8 2}$ & $\mathbf{0 , 5 5 2}$ & $\mathbf{0 , 9 3 7}$ & $\mathbf{0 , 7 7 6}$ & 0,012 & $\mathbf{0 , 7 6 5}$ & $\mathbf{0 , 7 7 3}$ & $-\mathbf{0 , 4 8 7}$ \\
C-CHN & 1 & $\mathbf{0 , 9 3 8}$ & 0,271 & $\mathbf{0 , 8 3 6}$ & $\mathbf{0 , 8 6 0}$ & 0,305 & $\mathbf{0 , 9 7 1}$ & $\mathbf{0 , 9 7 2}$ & $-0,334$ \\
N & & 1 & 0,332 & $\mathbf{0 , 7 9 8}$ & $\mathbf{0 , 8 4 1}$ & $\mathbf{0 , 5 0 9}$ & $\mathbf{0 , 9 2 5}$ & $\mathbf{0 , 9 5 6}$ & $-0,249$ \\
SB & & & 1 & 0,241 & 0,130 & $-0,241$ & 0,266 & 0,281 & $\mathbf{- 0 , 3 9 4}$ \\
H & & & & 1 & $\mathbf{0 , 8 6 7}$ & 0,147 & $\mathbf{0 , 7 9 6}$ & $\mathbf{0 , 8 0 8}$ & $-0,374$ \\
C-FAH & & & & & 1 & 0,305 & $\mathbf{0 , 7 9 4}$ & $\mathbf{0 , 8 7 5}$ & $-0,208$ \\
C-FAF & & & & & 1 & 0,295 & 0,364 & 0,367 \\
C-HUM & & & & & & 1 & $\mathbf{0 , 9 5 9}$ & $-\mathbf{0 , 4 0 3}$ \\
MO & & & & & & & & 1 & $-0,344$ \\
\hline
\end{tabular}

C-FAF: carbono da fração ácido fúlvico; C-FAH: carbono da fração ácido húmico; C-HUM: carbono da fração humina; C-CHN: carbono total determinado pelo analisador elementar; MO: matéria orgânica determinada em forno mufla; T: capacidade de troca de cátions do solo; SB: soma de bases; $\mathrm{H}^{+}$: hidrogênio; P: teor de P Mehlich-1. *Valores em negrito indicam significância a $0,05 \%$.

frações na geração de cargas, contribuindo com a capacidade de troca catiônica do solo (CTC) e aumentando a retenção de nutrientes e a complexação de cátions metálicos. Resultados semelhantes foram observados por Valladares et al. (2007) e Cunha et al. (2009) em diferentes classes de solos tropicais.

Foi verificada alta correlação entre o C-CHN e o N, C-FAH, C-HUM e MO, não sendo, porém, significativa para o C-FAF (Quadro 4). Segundo Schnitzer (1982), os ácidos húmicos em associação com coloides do solo formam complexos insolúveis em $\mathrm{pH}$ inferior a 6,5, possibilitando a imobilização e,ou, o acúmulo dessa fração em solos ácidos. $\mathrm{O} \mathrm{N}$ apresentou elevada correlação com C-FAH, C-HUM, C-CHN e MO. A relação entre os teores de $\mathrm{N}$ e o C-FAH (Figura 1) indica que essas frações estão estreitamente ligadas nos Organossolos (Figura 1). Esse resultado é relevante para avaliar a disponibilidade de $\mathrm{N}$ em Organossolos, uma vez que, em geral, a alta relação $\mathrm{C} / \mathrm{N}$ representa uma limitação para o manejo da adubação nitrogenada.

A SB apresentou correlação negativa e significativa com o teor de P, como também observado por Valladares et al. (2003). Alguns autores sugerem que em

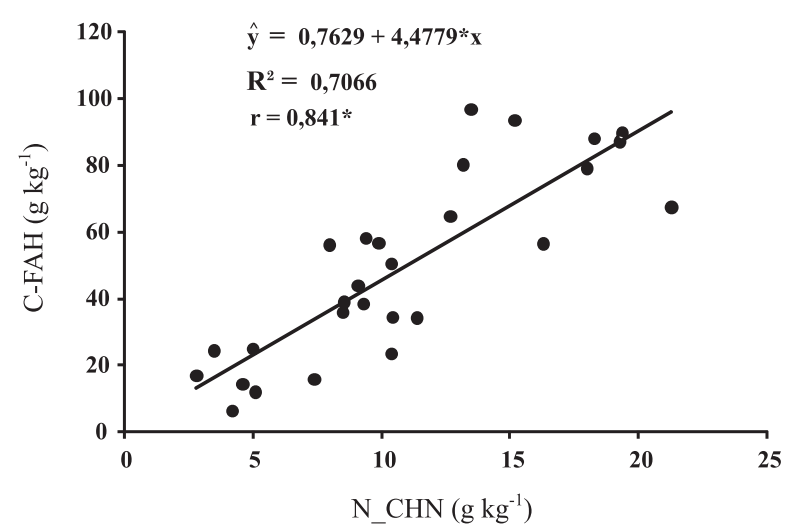

Figura 1. Relação entre os teores de $\mathrm{N}$ determinados pelo CHN e o carbono da fração ácido húmico (C-FAH) nos Organossolos.
Organossolos com maior fertilidade natural é intensificada a transformação da MOS, com maior produção de ácidos fúlvicos; esse processo aumentaria a produção de gases, como $\mathrm{CH}_{4}, \mathrm{CO}_{2}$ e $\mathrm{N}_{2} \mathrm{O}$, quando drenados (Regina et al., 1998). Contudo, não foi observada, para os perfis estudados, correlação entre a SB e o C da fração ácido fúlvico ou de outras frações da matéria orgânica. Ao contrário, altos valores de C-FAF e da SB foram observados nos perfis RJ02 e RJ08, que não foram drenados e apresentam menor grau de transformação da matéria orgânica, expressa pela presença de fibras.

\section{Atributos químicos}

Os valores de pH em água variaram de 4,0 a 5,1, sempre superiores (0,3 a 0,8 unidades) ao $\mathrm{pH}$ em $\mathrm{KCl}$, que variou de 3,5 a 4,5 (Quadro 5), estando os métodos correlacionados $(r=0,9414 ; \mathrm{p}<0,00)$. Estudando Histosols da Flórida, Zelazny \& Carlisle (1974) constataram variações de $\mathrm{pH}$ em $\mathrm{KCl}$ entre 0,4 e 0,7 unidades menores que o pH em água. Os valores de $\mathrm{pH}$ em água estão dentro da faixa reportada por Perez et al. (2009): 3,0 a 5,9. Já Volk \& Schnitzer (1973), em estudo sobre subsidência em Histosols na Flórida, encontraram valores de $\mathrm{pH}$ em água de 5,4 a 7,9.

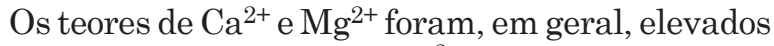
(Quadro 5). Os teores de $\mathrm{Ca}^{2+}$ variaram de 0,3 a $11,5 \mathrm{cmol}_{\mathrm{c}} \mathrm{dm}^{-3}$, com média de $4,8 \mathrm{cmol}_{\mathrm{c}} \mathrm{dm}^{-3}$, desviopadrão de 3,2 e alto coeficiente de variação (66,8 \%). Os teores de $\mathrm{Mg}^{2+}$ variaram de 1,1 a 9,2 $\mathrm{cmol}_{\mathrm{c}} \mathrm{dm}^{-3}$, com média de $3,8 \mathrm{cmol}_{\mathrm{c}} \mathrm{dm}^{-3}$, desvio-padrão de $2,3 \mathrm{e}$ alto coeficiente de variação $(62,2 \%)$. Em solos de altitude, Benites (2001) encontrou teores baixos de $\mathrm{Ca}^{2+}$

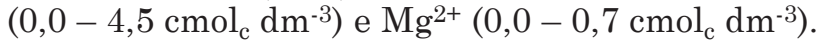
Ao contrário, Galvão \& Vahl (1996) encontraram altos teores de $\mathrm{Ca}^{2+}\left(4,0-32,7 \mathrm{cmol}_{\mathrm{c}} \mathrm{dm}^{-3}\right)$ e $\mathrm{Mg}^{2+}(3,0-$ $\left.62,6 \mathrm{cmol}_{\mathrm{c}} \mathrm{dm}^{-3}\right)$.

Os elevados teores de $\mathrm{Ca}^{2+}$ em vários perfis podem ser explicados pela contribuição da fração mineral dos solos e pela posição topográfica, em área onde é favorecida a adição de nutrientes, além da elevada capacidade de troca de cátions do solo; portanto, maior 
capacidade de reter, em ambas as frações (orgânica e mineral), esses nutrientes. Nos Organossolos em ambiente de altitude, cuja formação é favorecida pelas baixas temperaturas sem a contribuição de sedimentos, e onde o material de origem da fração mineral é pobre em bases, como nos solos estudados por Benites (2001), ocorrem baixos teores de $\mathrm{Ca}^{2+}$ e de outras bases. Em muitos horizontes os teores de $\mathrm{Mg}^{2+}$ são maiores que os de $\mathrm{Ca}^{2+}$, e o mesmo ocorre entre os teores de $\mathrm{Na}^{+}$e os de $\mathrm{K}^{+}$; esse efeito possivelmente esteja relacionado à influência de sedimentos marinhos ou lagunares, pela relativa proximidade de regiões costeiras, ou, ainda, pode fazer parte da composição do material de origem sedimentar de tempos pretéritos. Quanto ao perfil PR06, os elevados teores de nutrientes podem estar relacionados à exploração agrícola ou de indústrias de adubos em áreas próximas ao local de ocorrência do Organossolo e mais elevadas na paisagem.

Os teores de $\mathrm{K}^{+}\left(0,0-1,3 \mathrm{cmol}_{\mathrm{c}} \mathrm{dm}^{-3}\right)$ (Quadro 5) foram baixos, como os encontrados por Galvão \& Vahl (1996), predominando valores inferiores a $1,8 \mathrm{cmol}_{\mathrm{c}} \mathrm{dm}^{-3}$. Nos trabalhos desses autores os teores de $\mathrm{Na}^{+}$também foram baixos, semelhantes aos observados $\left(0,0-1,8 \mathrm{cmol}_{\mathrm{c}} \mathrm{dm}^{-3}\right)$ neste estudo. Segundo eles, apesar da alta CTC dos Organossolos, a retenção de cátions monovalentes é menor em relação aos demais cátions, justificando os reduzidos teores dos elementos $\mathrm{K}^{+}$e $\mathrm{Na}^{+}$. Exceções ocorrem em solos das planícies litorâneas, com maior influência da adição de sais pelas marés.

Quadro 5. Valores de pH e atributos químicos dos Organossolos nos Estados do Rio de Janeiro, Maranhão e Paraná

\begin{tabular}{|c|c|c|c|c|c|c|c|c|c|c|c|}
\hline Perfil & Horizonte & pH $\mathrm{H}_{2} \mathrm{O}$ & pH KCl & $\mathrm{Ca}^{2+}$ & $\mathrm{Mg}^{2+}$ & $\mathbf{K}^{+}$ & $\mathrm{Al}^{3+}$ & $\mathbf{H}+\mathbf{A l}$ & $\mathbf{T}$ & $\mathbf{S}$ & V \\
\hline & & & & \multicolumn{7}{|c|}{$-\mathrm{cmol}_{\mathrm{c}} \mathrm{dm}^{-3}$} & $\%$ \\
\hline RJ02 & Hdo & 3,95 & 3,50 & 1,00 & 1,53 & 0,21 & 3,80 & 32,01 & 35,4 & 3,4 & 10 \\
\hline RJ02 & Ho1 & 4,10 & 3,67 & 3,40 & 4,83 & 0,29 & 4,43 & 51,22 & 61,5 & 10,3 & 17 \\
\hline RJ02 & Ho2 & 4,26 & 3,77 & 3,30 & 4,90 & 0,29 & 4,50 & 57,50 & 67,8 & 10,3 & 15 \\
\hline RJ08 & Hdo & 4,13 & 3,79 & 8,67 & 3,03 & 0,12 & 2,73 & 34,49 & 46,4 & 12,0 & 26 \\
\hline RJ08 & Ho1 & 4,05 & 3,77 & 10,30 & 6,33 & 0,11 & 3,27 & 40,33 & 57,3 & 16,9 & 30 \\
\hline RJ08 & Ho2 & 4,47 & 4,04 & 10,53 & 9,13 & 0,11 & 2,07 & 47,78 & 67,7 & 20,0 & 29 \\
\hline RJ01 & Hd1 & 4,84 & 4,32 & 0,50 & 1,13 & 0,27 & 0,90 & 15,18 & 17,5 & 2,3 & 13 \\
\hline RJ01 & $\mathrm{Hd} 2$ & 4,71 & 4,23 & 0,33 & 1,67 & 0,19 & 0,73 & 11,22 & 13,8 & 2,5 & 18 \\
\hline RJ01 & $\mathrm{Cg} 1$ & 4,34 & 3,84 & 0,40 & 2,73 & 0,14 & 3,43 & 20,63 & 24,3 & 3,6 & 15 \\
\hline RJ01 & $\mathrm{Cg} 2$ & 4,25 & 3,76 & 0,30 & 1,47 & 0,14 & 4,21 & 15,02 & 17,3 & 2,2 & 13 \\
\hline RJ01 & $2 \mathrm{Hbd} 1$ & 4,36 & 3,98 & 0,47 & 1,60 & 0,14 & 5,50 & 20,63 & 23,2 & 2,6 & 11 \\
\hline RJ01 & $2 \mathrm{Hbd} 2$ & 4,05 & 3,58 & 2,13 & 3,63 & 0,14 & 4,97 & 51,15 & 57,7 & 6,6 & 11 \\
\hline RJ01 & $2 \mathrm{Hbd} 3$ & 4,10 & 3,78 & 0,90 & 1,70 & 0,13 & 5,33 & 45,87 & 49,0 & 3,1 & 6 \\
\hline RJ03 & Hdp1 & 5,04 & 4,40 & 6,60 & 3,90 & 0,34 & 0,87 & 17,16 & 29,0 & 11,8 & 41 \\
\hline RJ03 & Hdp2 & 4,94 & 4,20 & 5,70 & 2,83 & 0,20 & 1,37 & 18,15 & 27,6 & 9,4 & 34 \\
\hline RJ03 & $\mathrm{Cg}$ & 4,08 & 3,88 & 2,67 & 2,97 & 0,24 & 1,63 & 23,10 & 29,7 & 6,6 & 22 \\
\hline RJ0 3 & $2 \mathrm{Hbd}$ & 4,81 & 4,16 & 4,47 & 2,23 & 0,24 & 1,50 & 25,41 & 32,5 & 7,1 & 22 \\
\hline RJ03 & $2 \mathrm{Cbg}$ & 4,10 & 3,86 & 3,03 & 2,43 & 0,13 & 1,89 & 29,04 & 35,0 & 5,9 & 17 \\
\hline RJ03 & $3 \mathrm{Hbd}$ & 4,47 & 3,89 & 8,80 & 5,17 & 0,11 & 2,87 & 42,90 & 57,2 & 14,3 & 25 \\
\hline RJ04 & Hdp1 & 4,99 & 4,23 & 4,33 & 2,67 & 0,31 & 0,97 & 24,59 & 32,0 & 7,4 & 23 \\
\hline RJ04 & Hdp2 & 4,81 & 4,16 & 4,47 & 2,23 & 0,24 & 1,50 & 25,41 & 32,5 & 7,1 & 22 \\
\hline RJ04 & $\mathrm{Cg}$ & 4,10 & 3,99 & 3,00 & 2,57 & 0,18 & 1,82 & 18,15 & 30,3 & 5,6 & 19 \\
\hline RJ04 & $2 \mathrm{Hbd}$ & 4,78 & 4,12 & 5,53 & 3,00 & 0,15 & 3,83 & 37,62 & 46,5 & 8,9 & 19 \\
\hline RJ04 & $2 \mathrm{Cbg}$ & 4,10 & 3,96 & 3,00 & 2,70 & 0,14 & 3,67 & 20,46 & 26,5 & 6,0 & 23 \\
\hline RJ04 & $3 \mathrm{Hbd} 1$ & 4,66 & 4,02 & 6,20 & 3,60 & 0,13 & 3,50 & 37,79 & 48,0 & 10,3 & 21 \\
\hline RJ04 & $3 \mathrm{Hbd} 2$ & 4,62 & 4,04 & 11,47 & 4,60 & 0,14 & 2,07 & 43,40 & 60,0 & 16,6 & 28 \\
\hline MA05 & Hdo1 & 4,30 & 3,79 & 9,00 & 9,23 & 1,30 & 2,73 & 19,31 & 39,6 & 20,3 & 51 \\
\hline MA05 & Hdo2 & 4,36 & 3,72 & 7,07 & 7,90 & 0,96 & 4,97 & 28,88 & 45,3 & 16,4 & 36 \\
\hline MA05 & $\mathrm{Cg}$ & 5,04 & 4,20 & 1,70 & 3,37 & 0,67 & 4,47 & 14,85 & 20,6 & 5,7 & 28 \\
\hline MA05 & $2 \mathrm{Hbd} 1$ & 4,31 & 3,72 & 5,63 & 8,73 & 1,15 & 5,17 & 25,41 & 41,4 & 16,0 & 39 \\
\hline MA05 & $2 \mathrm{Hbd} 2$ & 4,30 & 3,72 & 5,83 & 8,20 & 0,74 & 3,07 & 23,10 & 38,2 & 15,1 & 40 \\
\hline PR06 & Hdo1 & 5,10 & 4,46 & 8,13 & 2,60 & 0,13 & 1,20 & 27,23 & 38,1 & 10,9 & 29 \\
\hline PR06 & Hdo2 & 4,50 & 4,13 & 6,97 & 3,07 & 0,06 & 0,80 & 22,99 & 33,1 & 10,1 & 31 \\
\hline PR06 & Hdo3 & 4,73 & 4,04 & 6,43 & 2,03 & 0,02 & 2,50 & 21,18 & 29,7 & 8,5 & 29 \\
\hline PR06 & Hdo4 & 5,03 & 4,42 & 6,30 & 1,73 & 0,03 & 2,80 & 19,09 & 27,1 & 8,1 & 30 \\
\hline Máxim & & 5,1 & 4,5 & 11,5 & 9,2 & 1,3 & 5,5 & 57,5 & 67,8 & 20,3 & 51,0 \\
\hline Mínimo & & 4,0 & 3,5 & 0,3 & 1,1 & 0,0 & 0,7 & 11,2 & 13,8 & 2,2 & 6,0 \\
\hline Média & & 4,5 & 4,0 & 4,8 & 3,8 & 0,3 & 2,9 & 28,8 & 38,3 & 9,3 & 24,1 \\
\hline $\mathrm{Dp}$ & & 0,4 & 0,2 & 3,2 & 2,3 & 0,3 & 1,5 & 12,2 & 14,6 & 5,1 & 10,1 \\
\hline CV (\%) & & 7,9 & 6,2 & 66,8 & 62,2 & 108,2 & 51,1 & 42,4 & 38,3 & 55,5 & 41,8 \\
\hline
\end{tabular}


A acidez trocável $\left(\mathrm{Al}^{3+}\right)$ variou de 0,7 a $5,5 \mathrm{cmol}_{\mathrm{c}} \mathrm{dm}^{-3}$, decrescendo em profundidade e apresentando correlação negativa com o $\mathrm{pH}$ em água e em $\mathrm{KCl}\left(\mathrm{r}=-0,7203^{* * * *}\right.$, $\mathrm{r}=-0,7666^{* * *}$, respectivamente). Assim como em outras classes de solos, nos Organossolos, com o aumento do $\mathrm{pH}$, ocorre a redução do $\mathrm{Al}^{3+}$ em solução.

A acidez potencial $(\mathrm{H}+\mathrm{Al})$ foi muito alta, variando de 11,2 a $57,5 \mathrm{cmol}_{\mathrm{c}} \mathrm{dm}^{-3}$ (Quadro 5) - valores muito além dos mencionados por Dolman \& Buol (1967). Segundo esses autores, o teor de $\mathrm{H}^{+}$em Organossolos na Carolina do Norte (Estados Unidos) variou de 0 a $2,5 \mathrm{cmol}_{\mathrm{c}} \mathrm{dm}^{-3}$ em solos bem drenados e de 2 a $12 \mathrm{cmol}_{\mathrm{c}} \mathrm{dm}^{-3}$ nos solos com má drenagem. Esse padrão diferiu dos reportados neste trabalho e dos encontrados por Ebeling et al. (2008), que observaram variação nos valores de $\mathrm{H}^{+}$em várzeas de 10,0 a $83,6 \mathrm{cmol}_{\mathrm{c}} \mathrm{dm}^{-3}$ e em ambientes altimontanos, com solos bem drenados, de 11,9 a 83,6 $\mathrm{cmol}_{\mathrm{c}} \mathrm{dm}^{-3}$. Pereira et al. (2006) encontraram em Organossolos valores de $\mathrm{H}+\mathrm{Al}$ variando de 10,40 a $89,10 \mathrm{cmol}_{\mathrm{c}} \mathrm{dm}^{-3}$. O valor de $\mathrm{H}^{+}$apresentou correlação positiva e significativa (Quadro 4) com os teores de C-CHN, C-FAH, C-HUM e MO, evidenciando a alta relação entre a acidez e CTC e com o teor de $\mathrm{C}$ dos Organossolos.

A SB variou de 2,2 a $20,3 \mathrm{cmol}_{\mathrm{c}} \mathrm{dm}^{-3}$, com média de $9,3 \mathrm{cmol}_{\mathrm{c}} \mathrm{dm}^{-3}$. Dos 28 horizontes, cinco apresentaram valor SB menor ou igual a $5,0 \mathrm{cmol}_{\mathrm{c}} \mathrm{dm}^{-3}$, indicando a menor fertilidade natural e exigência de adubações ( $\mathrm{Ca}, \mathrm{Mg}$ e $\mathrm{K}$ ) para seu uso agrícola. Entretanto, a maioria dos horizontes apresentou valores $\mathrm{SB}$ altos, maiores que $10 \mathrm{cmol}_{\mathrm{c}} \mathrm{dm}^{-3}$. Nesses Organossolos, a drenagem irá propiciar a rápida degradação, pela transformação da matéria orgânica, favorecida pela disponibilidade de nutrientes para os organismos do solo.

O valor T variou de 13,8 a $67,8 \mathrm{cmol}_{\mathrm{c}} \mathrm{dm}^{-3}$, com média de $38,3 \mathrm{cmol}_{\mathrm{c}} \mathrm{dm}^{-3}$. Das 28 amostras, todas apresentaram valor T entre 27 e $67 \mathrm{cmol}_{\mathrm{c}} \mathrm{dm}^{-3}$, valor alto quando comparado ao dos solos minerais em ambiente tropical. A elevada CTC nos Organossolos deve-se à presença dos coloides orgânicos, com grande superfície específica e grande quantidade de sítios de troca (Brady, 1999). Souza Júnior et al. (2001) encontraram teores de $\mathrm{H}^{+}$de 3,3 a $39,9 \mathrm{cmol}_{\mathrm{c}} \mathrm{dm}^{-3} \mathrm{e}$ valor $\mathrm{T}$ variando de 22,9 a $110,2 \mathrm{cmol}_{\mathrm{c}} \mathrm{dm}^{-3}$. O valor $\mathrm{T}$ apresentou correlação positiva e significativa com C-CHN, C-FAH, C-HUM e MO (Quadro 4). Padrão similar foi encontrado por Conceição (1989), estudando Organossolos no Estado do Rio de Janeiro. $\mathrm{O}$ valor $\mathrm{V}$ variou de 6 a $51 \%$, com $33 \%$ dos horizontes com $\mathrm{V}$ igual ou inferior a 20 e $96 \%$ igual ou inferior a $50 \%$, expressando o predomínio do $\mathrm{H}^{+}$no complexo sortivo e, consequentemente, o caráter distrófico nos Organossolos, embora a SB seja melhor indicador de fertilidade dos Organossolos que a saturação por bases, pela influência dos altos teores de matéria orgânica na acidez do solo.

Alguns resultados dos atributos químicos e das frações da matéria orgânica dos Organossolos foram comparados tendo como referência os ambientes de formação e influência antrópica. A área do perfil RJ01 foi queimada nos últimos anos e apresentou redução, na camada superficial, dos teores de $\mathrm{C}$ nas frações da matéria orgânica e, principalmente, no valor da relação C-FAH/C-FAF, bem como os atributos SB e T. Os perfis RJ03 e RJ04, com mais intenso uso agrícola, também apresentaram redução do $\mathrm{C}$ das frações orgânicas e da relação C-FAH/C-FAF na camada superficial, porém os teores de $\mathrm{Ca}^{2+} \mathrm{e} \mathrm{Mg}^{2+} \mathrm{e}$ $\mathrm{V}$ aumentaram, devido à calagem. O perfil MA05, localizado em ambiente lacustre inundado em parte do ano, recebe adições de sedimentos e solutos de diversas fontes, o que explica os altos teores de nutrientes e elevados valores T e V. Como em outros perfis, a relação C-FAH/C-FAF foi menor no horizonte superficial e também apresentou predomínio do CHUM. O perfil PR06, em ambiente de várzea, porém de elevada altitude (planalto), mostra redução do conteúdo de $\mathrm{C}$ nas frações húmicas e de $\mathrm{MO}$ em profundidade, com comportamento semelhante para o teor de cálcio e de SB e T.

\section{CONCLUSÕES}

1. Os teores de $\mathrm{C}$ nas frações da MOS diferiram entre si e entre os perfis de Organossolos, havendo predomínio da fração humina, seguida da fração ácido húmico.

2. Menores valores da relação C-FAH/C-FAF foram observados nos horizontes superficiais, à exceção do perfil RJ02, indicando a influência antrópica pelas queimadas ou cultivo agrícola com a drenagem do perfil sobre os Organossolos, o que demonstra a fragilidade desses solos.

3. Os atributos químicos variaram com o efeito das queimadas, a intensidade de uso agrícola e o ambiente de formação, porém, em geral, os Organossolos apresentaram baixa fertilidade. A queima e o uso agrícola reduziram os valores da CTC e do $\mathrm{H}^{+}$, aumentando o $\mathrm{pH}$ do solo e favorecendo perdas de C. Os menores teores de matéria orgânica, C-CHN e de C nas substâncias húmicas foram observados nos horizontes superficiais dos perfis com maior efeito de queimadas ou intensidade de uso agrícola e drenagem.

\section{LITERATURA CITADA}

BENITES, V.M.; SCHAEFER, C.E.R.G.; MENDONÇA, E.S. \& MARTIN NETO, L. Caracterização da matéria orgânica e micromorfologia de solos sob campos de altitude no Parque Estadual da Serra do Brigadeiro. R. Bras. Ci. Solo, 25:661674, 2001.

BENITES, V.M.; MADARI, B. \& MACHADO, P.L.O.A. Extração e fracionamento quantitativo de substâncias húmicas do solo: Um procedimento simplificado de baixo custo. Rio de Janeiro, 2003. 13p. (Comunicado Técnico, 14) 
BENITES, V.M. Caracterização química e espectroscópica da matéria orgânica e suas relações com a gênese de solos da Serra do Brigadeiro, Zona da Mata mineira. Viçosa, MG, Universidade Federal de Viçosa, 1998. 125p. (Tese de Mestrado)

BRADY, N.C. Natureza e Propriedades dos Solos. 7. eds. Rio de Janeiro, Freitas Bastos, 1989. 554p.

BREEMEN, N. \& BUURMAN, P. Soil formation. 2.ed. Dordrecht, Kluwer Academic Publishers, 2002. 404p.

CERRI, C. \& VOLKOFF, B. Matéria orgânica de três solos dos campos inundáveis da Ilha de Marajó/PA. R. Bras. Ci. Solo, 12:93-100, 1988.

CONCEIÇÃO, M. Natureza do húmus e caracterização de solos com elevado teor de matéria orgânica da região de Itaguaí - Santa Cruz, RJ. Itaguaí, Universidade Federal Rural do Rio de Janeiro, 1989. 169p. (Tese de Mestrado)

CUNHA, T.J.F.; MADARI, B.E.; CANELLAS, L.P.; RIBEIRO, L.P.; BENITES, V.M. \& SANTOS, G.A. Soil organic matter and fertility of anthropogenic dark earths (terra preta de índio) in the Brazilian Amazon basin. R. Bras. Ci. Solo, 33:85-93, 2009.

DABLIN, B. Les matières organiques dans les sols tropicaux normalement drainès. Cah. ORSTOM. Sér. Pédol., 18:197 215, 1981.

DOLMAN, J.D. \& BUOL, S.W. A study of organic soils (Histosols): In the tidewater region of North Carolina. North Carolina, North Carolina Agricultural Experimental Station, 1967. 47p. (Technical Bulletin, 181)

DUChAufour, P.H. \& SOUCHIER B. Pédogenèse et classification. Paris, Masson, 1977. II Tomo. 477p.

EBELING, A.G.; ANJOS, L.H.C.; PEREZ, D.V.; PEREIRA, M.G. \& VALLADARES, G.S. Relação entre acidez e outros atributos químicos em solos com teores elevados de matéria orgânica. Bragantia, 67:261-266, 2008.

EMPRESA BRASILEIRA DE PESQUISA AGROPECUÁRIA EMBRAPA. Centro Nacional de Pesquisa de Solos. Serviço nacional de levantamento e conservação do solo. Manual de métodos de análise de solo. Rio de Janeiro, 1997. 212 p.

EMPRESA BRASILEIRA DE PESQUISA AGROPECUÁRIA EMBRAPA. Centro Nacional de Pesquisa de Solos. Sistema brasileiro de classificação de solos. 2.ed. Brasília, Embrapa Produção da Informação; Rio de Janeiro: 2006. 306p.

FONTANA, A.; PEREIRA, M.G.; ANJOS, L.H.C. \& BENITES, M.B. Distribution of organic carbon in the humic fractions of diagnostic horizons from brazilian soils. Comm. Soil Sci. Plant Anal., 39:951-971, 2008b.

FONTANA, A.; BENITES, M.B.; PEREIRA, M.G. \& ANJOS, L.H.C. Substâncias húmicas com suporte à classificação de solos brasileiros. R. Bras. Ci. Solo, 32:2073-2080, 2008 a.

GALVÃO, F.A.D. \& VAHL, L.C. Calibração do método SMP para solos orgânicos. R. Bras. Agropec., 2:121-131, 1996.

GARCIA, M.J. Potencialidade e aplicação de turfas. R. Univ. Guarulhos, 1:16-30, 1996.
KAKEI, M. \& CLIFFORD, P.E. Short-term effects of lime application on soil properties and fine-root characteristics for a 9-year-old Sitka spruce plantation growing on a deep peat soil. Forestry, 75:37-50, 2002.

KALBITZ, K. \& GEYER, S. Different effects of peat degradation on dissolved organic carbon and nitrogen. Org. Geochem., 33:319-326, 2002.

KONONOVA, M.M. Materia orgânica del suelo; su natureza, propriedades y métodos de investigation. Barcelona, Oikos - Tau, 1982. 365p.

NELSON, D.W. \& SOMMERS, L.E. Total carbon, organic carbon and organic matter. In: SPARKS, D.L.; PAGE, A.L.; HELMKE, P.A.; LOEPPERT, R.H.; SOLTANPOUR, P.N.; TABATABAI, M.A.; JOHNSTON, C.T. \& SUMMER, M.E., eds. Methods of soil analysis. Chemical methods. Madison, Soil Science Society of America/American Society of Agronomy, 1996. Part 3. p.961-1009. (Book Series, 5)

PEREIRA, M.G.; ANJOS, L.H.C. \& VALLADARES, G.S. Organossolos: Ocorrência, gênese, classificação, alterações pelo uso agrícola e manejo. In: VIDALTORRADO, P., ALLEONI, L.R.F.; COOPER, M.; SILVA, A.P. \& CARDOSO, E.J., orgs. Tópicos em ciência do solo. Viçosa, MG, Sociedade Brasileira de Ciência do Solo, 2005. v.4. p.233-276.

PEREIRA, M.G.; EBELING, A.G.; VALLADARES, G.S.; ANJOS, L.H.C. \& ESPINDULA J.R.A. Estimativa da acidez potencial pelo método do $\mathrm{pH}$ SMP em solos com elevado teor de matéria orgânica. Bragantia, 65:487-493, 2006.

PEREZ, D.V.; ANJOS, L.H.C.; EBELING, A.G. \& PEREIRA, M.G. Comparison of H/Al stoichiometry of mineral and organic soils in Brazil. R. Bras. Ci. Solo, 33:1071-1076, 2009.

REGINA, K.; NYKÄNEN, H.; MALJANEN, M. \& SILVOLA, J. Emissions of $\mathrm{N}_{2} \mathrm{O}$ and $\mathrm{NO}$ and net nitrogen mineralization in a boreal forested peatland treated with different nitrogen compounds. Can. J. For. Res., v.28, p.132-140, 1998.

SANTOS, R.D.; LEMOS, R.C.; SANTOS, H.G.; KER, J.C. \& ANJOS, L.H.C. Manual de descrição e coleta de solo no campo. 5.ed. Viçosa, MG, Sociedade Brasileira de Ciência do Solo, 2005. 92p.

SCHNITZER, M. Organic matter characterization. In: PAGE, A.L.; MILLER, R.H. \& KEENEY, D.R., eds. Methods of soil analysis: Chemical and microbiological properties. 2.ed. Madison, American Society of Agronomy/SSSA, 1982. Part 2: p.581-594. (Agronomy, 9).

SOUZA JÚNIOR, V.S.; RIBEIRO, M.R. \& OLIVEIRA, L.B. Propriedades químicas e manejo de solos tiomórficos da várzea do Rio Coruripe, Estado de Alagoas. R. Bras. Ci. Solo, 25:811-822, 2001.

SILVA, A.C.; HORÁK, I.; TORRADO, P.C.; CORTIZAS, A.M.; RACEDO, J.R. \& CAMPOS, J.R.R. Turfeiras da serra do espinhaço meridional - MG. II - Influência da drenagem na composição elementar e substâncias húmicas. R. Bras. Ci. do Solo, 33:1399-1408, 2009. 
STEVENSON, F.J. Humus chemistry: Genesis, composition, reactions. 2.ed. New York, John Wiley \& Sons, 1994 443 p.

VALLADARES, G.S. Caracterização de Organossolos, auxílio à sua classificação. Seropédica, Universidade Federal Rural do Rio de Janeiro, 2003. 142p. (Tese de Doutorado)

VALLADARES, G.S.; PEREIRA, M.G.; ANJOS, L.H.C.; BENITES, V.M.; EBELING, A.G. \& MOUTA, R.O. Humic substance fractions and attributes of Histosols and related high-organic-matter soils from Brazil. Comm. Soil Sci. Plant Anal., 38:763-777, 2007.

VALLADARES, G.S.; PEREIRA, M.G.; ANJOS, L.H.C. \& EBELING, A.G. Caracterização de solos brasileiros com elevados teores de material orgânico. Magistra, 20:95$104,2008$.
VOLK, B.G. \& SCHNITZER, M. Chemical and spectroscopic methods for assessing subsidence in Florida Histosols. Soil Sci. Am. Proc., 37:886-888, 1973.

ZELAZNY, L.W. \& CARLISLE, V.W. Physical, chemical, elemental, and oxygen-containing functional group analysis of selected Florida Histosols. In: AANDAHL, A.R.; BUOL, S.W.; HILL, D.E. \& BAILEY, H.H., eds. Histosols: Their characteristics, classification, and use. Madison, Soil Science Society of America, 1974 p.63-78. (Special Publication, 6) 